\title{
A New Mitochondrial DNA Mutation in ND3 Gene Causing Severe Leigh Syndrome with Early Lethality
}

\author{
MARCO CRIMI, ALEXANDROS PAPADIMITRIOU, SARA GALBIATI, PHANI PALAMIDOU, \\ FRANCESCO FORTUNATO, ANDREINA BORDONI, URANIA PAPANDREOU, \\ DIMITRA PAPADIMITRIOU, GEORGE M. HADJIGEORGIOU, EURYDIKI DROGARI, \\ NEREO BRESOLIN, AND GIACOMO PIETRO COMI
}

\begin{abstract}
Centro Dino Ferrari [M.C., S.G., F.F., A.B., N.B., G.P.C.], Department of Neurological Sciences, University of Milan, I.R.C.C.S. Ospedale Maggiore Policlinico, Centro di Eccellenza per le malattie Neuro-Degenerative (CEND), 20122 Milano, Italy; Red Cross Hospital [A.P.], 115-26 Athens, Greece; School of Medicine [A.P., G.M.H.], University of Thessaly, 412-22 Larissa, Greece; First Department of Pediatrics [P.P., U.P., D.P., E.D.], University of Athens, St. Sophia's Children's Hospital, 115-27 Athens, Greece; and I.R.C.C.S. "Eugenio Medea” [N.B.], La Nostra Famiglia, 23842 Bosisio Parini (LC), Italy
\end{abstract}

\begin{abstract}
We describe a new mitochondrial DNA mutation in a male infant who presented clinical and magnetic resonance imaging features of Leigh syndrome and died at the age of 9 mo. The patient's development was reportedly normal in the first months of life. At the age of $5 \mathrm{mo}$, he presented severe generalized hypotonia, nystagmus, and absent eye contact. Laboratory examination showed increased lactate and pyruvate in both serum and cerebrospinal fluid. Brain magnetic resonance imaging revealed multiple necrotic lesions in the basal ganglia, brain stem, and thalamus. Muscle histopathology was unremarkable, whereas respiratory chain enzyme analysis revealed a severe complex I deficiency. The patient died after an acidotic coma at age 9 mo. Sequence analysis of the entire mtDNA disclosed a new
\end{abstract}

\section{ABSTRACT}

T10158C mutation with variable tissue heteroplasm (muscle: $83 \%$; blood: $48 \%$ ). The mutation was undetectable in the blood of his unaffected mother. The transition changes a serine residue into a proline, in a highly conserved region of the NADH dehydrogenase subunit 3 (ND3). This is the first description of a mitochondrial ND3 gene in Leigh syndrome with early lethality.

(Pediatr Res 55: 842-846, 2004)

\section{Abbreviations}

mtDNA, mitochondrial DNA

LS, Leigh syndrome

MRI, magnetic resonance imaging

np, nucleotide position
Leigh syndrome (LS) is a neurodegenerative disease of infancy and childhood that is characterized by symmetrical necrotic lesions in the brainstem, basal ganglia, and thalamus (1). The symptoms include psychomotor retardation, failure to thrive, vomiting, seizures, and respiratory failure. Laboratory findings reveal elevated lactate levels in blood and spinal fluid. In addition, defects in the pyruvate dehydrogenase and respiratory chain complexes (including complexes I, II, IV, and V) have been documented. Genetically, mutations in both mitochondrial (mtDNA) and nuclear DNA are involved in the

Received August 20, 2003; accepted December 5, 2003.

Correspondence: Dr. Marco Crimi, Ph.D., Dipartimento di Scienze Neurologiche (Pad.ne Ponti), Università di Milano, Via F. Sforza 35, 20122 Milano, Italy; e-mail: neurogene@policlinico.mi.it or marcreamy@tiscali.it

This research received support by "Progetto MIUR-CNR Genomica Funzionale" (to G.P.C.) and by "Ricerca Finalizzata 2002," Ministero della Salute, Italy (to G.P.C.).

DOI: 10.1203/01.PDR.0000117844.73436.68 pathogenesis of LS (2). Nevertheless, in more than half of LS patients, the pathogenesis cannot be identified.

Complex I is the largest multiprotein enzyme complex of the respiratory chain; it is embedded in the inner mitochondrial membrane and is partly protruding in the matrix and consists of at least 46 distinct subunits, seven of which are encoded by mtDNA. The main function of complex I is the transport of electrons from NADH to ubiquinone with simultaneous shunting of protons (3). Defects of complex I, involving mtDNA or nuclear encoded subunits, are reportedly the major cause of mitochondrial disease (4). We herein report a novel mtDNA mutation (T-to-C mutation at nucleotide position [np] 10158) associated with LS and isolated complex I deficiency in a young infant.

The proband was the second son of healthy and unrelated Greek parents. His mother had previously had several pregnancies prematurely terminated by spontaneous abortions. The family history was negative for neurologic diseases. After an 
uneventful pregnancy, an apparently normal infant was born at 35 wk of gestation, by normal delivery.

The patient's development was reportedly normal in the first months. When first seen at age $5 \mathrm{mo}$, his weight was $4900 \mathrm{~g}$, his length was $60 \mathrm{~cm}$, and his head circumference was $40 \mathrm{~cm}$. The patient showed severe hypotonia of the trunk and upper and lower extremities; he was unable to hold up his head and had nystagmus and no eye contact.

Laboratory examination showed increased lactic acid $(82.5$ $\mathrm{mg} / \mathrm{dL}$; n.v.: $5.7-22)$ and pyruvic acid $(1.7 \mathrm{mg} / \mathrm{dL}$; normal value (n.v.): $0.3-0.7$ ). The lactic acid of cerebrospinal fluid was also increased $(5.94 \mathrm{mg} / \mathrm{dL}$; n.v: $<2.1)$, as well as pyruvic acid $(0.328 \mathrm{mg} / \mathrm{dL}$; n.v.: <01). Blood amino-gram showed a slight increase of alanine, but the amino-gram of urine was normal. The serum long-chain fatty acids were also normal. Brain magnetic resonance imaging (MRI) revealed multiple necrotic lesions in the basal ganglia, brain stem, and thalamus (Fig. 1). Histopathologic study of skeletal muscle did not show ragged-red fibers, strongly succinate dehydrogenase-reactive blood vessels, or cytochrome c oxidase-deficient fibers. The patient died after an acidotic coma at age 9 mo.

\section{METHODS}

Direct sequence of total mtDNA. DNA extraction, PCR, and total mtDNA sequencing were done as described elsewhere (5).

Restriction fragment length polymorphism analysis of mtDNA T10158C mutation. The following sets of primers were used to detect the T-to-C mutation at np 10158. A light-strand primer, corresponding to np 9912-9937, and a modified heavystrand primer, corresponding to np 10159-10180 (5'-TATAGGGTCGAAGCCGCACTCGTAAGGGGTCG-3'), were used. The italicized positions represent a modification from the normal sequence to create a Taq $\alpha$ I restriction site (TCGA) to amplify the mutant sequences. The PCR condition was as follows: denaturing $94^{\circ} \mathrm{C}$ for $5 \mathrm{~min}$, annealing $58^{\circ}$ for $30 \mathrm{~s}$, extension at
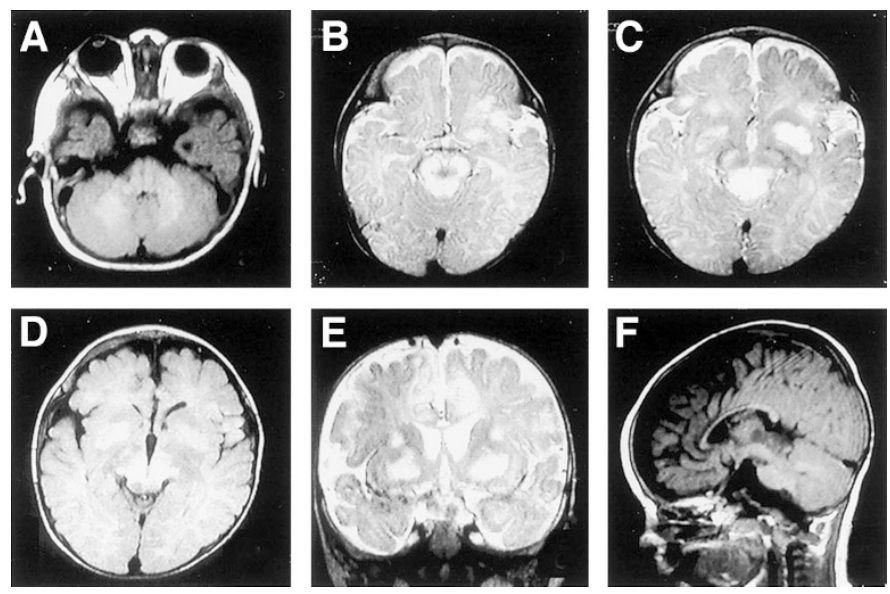

Figure 1. Brain MRI obtained at age 5 mo. MRI T1 images in the axial sections show the presence of the bilateral and symmetrical hyperintense alterations of the cerebellar hemispheres $(a)$ and of the mesencephalon, thalamus, and caudate nucleus $(d)$. Coronal sections: atrophy of corpus callo$\operatorname{sum}(f)$. MRI T2 images in the axial sections show the presence of the bilateral lesions of the mesencephalic tegmentum and periaqueductal gray matter $(b)$; of the mesencephalon, thalamus, and caudate nucleus $(c)$; and of the thalamus and caudate nucleus $(e)$. $72^{\circ}$ for $25 \mathrm{~s}$ for 30 cycles, and final extension for $5 \mathrm{~min}$. The amplified 268-bp fragment was digested with Taq $\alpha$ I to produce $246+22$-bp fragments from the wild-type sequence, whereas the mutant sequence remained undigested. These fragments were separated electrophoretically through a $4 \%$ low-melting agarose gel after ethidium bromide staining.

Spectrophotometric assays of respiratory chain enzyme activity. Skeletal muscle from specimen biopsy was liquid nitrogen conserved until biochemical analysis. Spectrophotometric determinations of enzyme activity, including NADHubiquinone 1 reductase, NADH-cytochrome c reductase, succinate-cytochrome c reductase, and cytochrome c oxidase were performed as described elsewhere (6).

\section{RESULTS}

Respiratory chain function. The biochemical assay of the patient's skeletal muscle respiratory chain enzymes showed a severe isolated complex I deficiency: $23 \%$ of mean control value (Fig. 2).

Molecular genetic analysis. No mtDNA rearrangements were detected by the long PCR method. Sequence analysis on total mtDNA in the patient revealed nine nucleotide changes with respect to the revised mtDNA normal sequence. Six were deemed as polymorphisms because they were silent mutations or were previously reported as such, according to a human mitochondrial genome database (7). Two homoplasmic synonymous nucleotide changes in coding regions (T6227C in COI and $\mathrm{T} 11152 G$ in ND4) were not present in 60 normal Italian and 40 normal Greek adults. These variants were homoplasmic in the proband's muscle- and blood-derived DNA, as well as in blood DNA of his mother. Among the novel nucleotide changes, a T-to-C mutation at np 10158 converts an evolutionarily conserved serine to a proline at codon 34 in the ND3 gene (NM_173710). Using a PCR-restriction fragment length polymorphism method, we did not detect this mutation in 100 healthy subjects. This method also confirmed the heteroplasmic nature of this mutation: the percentages of mutant-type mtDNA in the patient were $83 \%$ in muscle and $48 \%$ in blood (Fig. 3). The mutation was absent in the maternal bloodderived DNA.

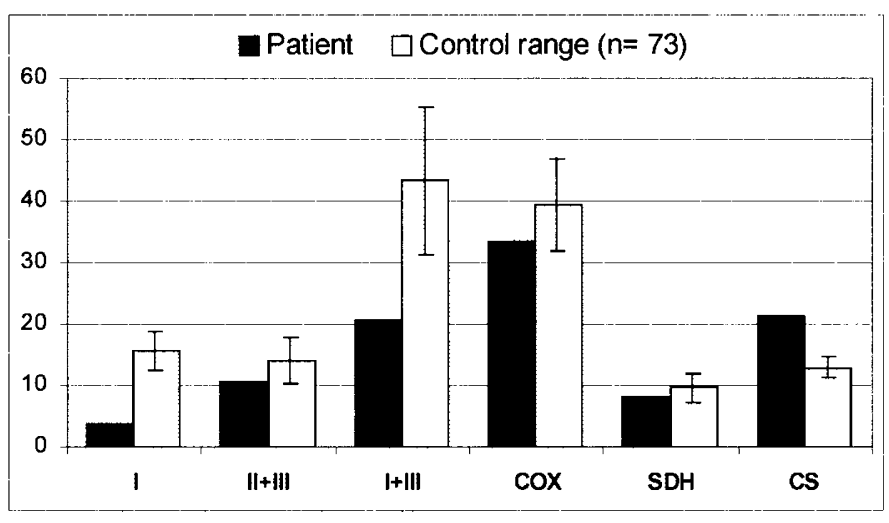

Figure 2. Respiratory chain enzyme activities in muscle homogenate. The results of each assay are visualized as nanomoles per minute per milligram of protein and normalized to the citrate synthase (CS) activity. SDH, succinate dehydrogenase. 
A

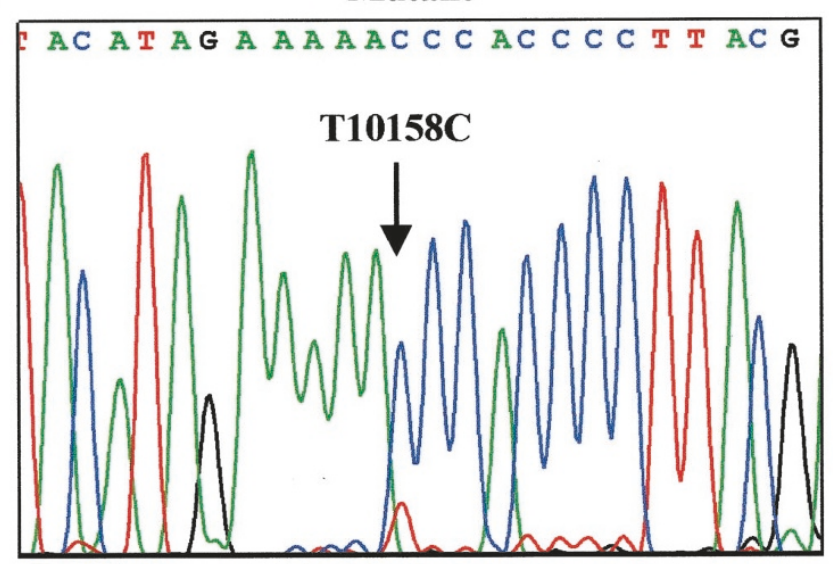

Wild-type

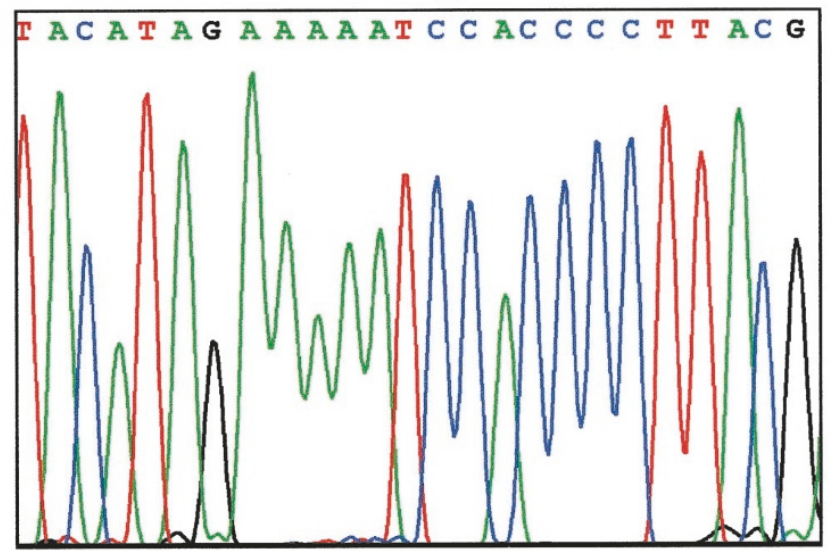

B

$\begin{array}{llllll}1 & 2 & 3 & 4 & 5\end{array}$

Mut. W-T
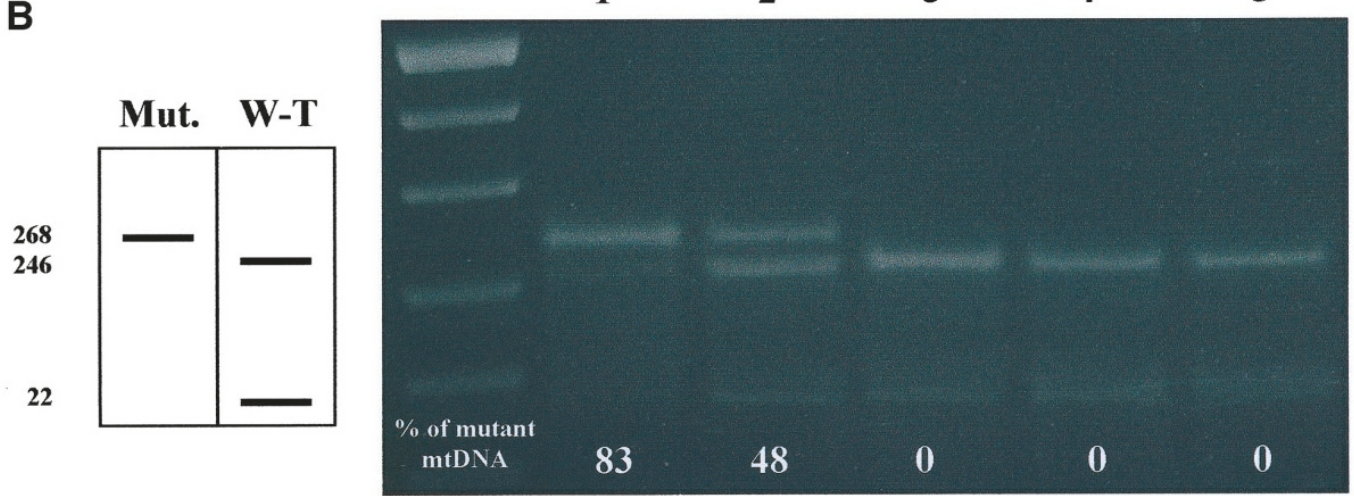

C

30

40

Human

I

I

Sheep

Bovine

FWLPQLNGYMEKSTPYECGFDPM

FWLPQLNVYSEKSTPYECGFDPM

FWLPQLNVYSEKSTPYECGFDPM

Pongo Py.

Horse

FWLPQLNPYMEKSDPYECGFDPA

Rabbit

FWLPQLNIYAEKSTPYECGFDPM

FWLPQLNIYSEKSS PYECGFDPM

Sus Scrofa

FWLPQLNAYSEKSTPYECGEDPM

Drome

Pan paniscus

Tamandua $T$.

FWLPQLNTYTEKSS PYECGFDPM

FWLPQLNSYMEKSNPYECGEDPM

FWLPQLNNYSEKSS PYECGFDPM

Colobus Gu.

FWLPQLNSYTEKSNPYECGFDPL

Oryctolagus

Talpa Europea

Rhinoceros

FWLPQLNIYSEKSSPYECGFDPM

FWLPQLNTYSEKSSPYECGFDPM

FWLPQLNIYTEKSSPYECGFDPM

Figure 3. (A) Electropherogram (left) from a selected ND3 region, showing the T-to-C transition in the muscle-derived DNA of the proband compared with a control (right). Arrows indicate the mutation at np 10158. (B) Restriction fragment length polymorphism analysis of the T10158C mutation. The substitution creates a new Taq $\alpha$ I restriction site. The Taq $\alpha$ I enzymes cuts the normal mtDNA sequence from nt 9912 to np 10180 into two fragments of 246 and 22 bp, respectively. The sequence is uncleaved in the mutated mtDNA. W-T, wild-type; Mut, mutated; 1, proband's muscle; 2, proband's blood; 3, blood-derived DNA from the proband's sister; 4, blood-derived DNA from the proband's mother; 5, normal control DNA. (C) Phylogenetic conservation of amino acid residue S-34 within the amino acid sequence from residue aa 22 to 44 of the ND3 protein. The S-34 amino acid residue is shown in red. Pongo Py, Pongo Pygmaeus; Drome, Drosophila Melanogaster; Tamandua T., Tamandua Tetradactyla; Colobus Gu., Colobus Guereza. 


\section{DISCUSSION}

Several distinct phenotypes are associated with isolated complex I deficiency: LS, LS-like, macrocephaly with progressive leukodystrophy, neonatal cardiomyopathy (hypertrophic and congestive) with lactic acidosis, and unspecified encephalomyopathy subdivided into stable and progressive variants (fatal infantile lactic acidosis) (3).

Complex I deficiency represents a major cause of LS and LS-like syndrome according to patient series of referral centers $(3,8,9)$. The molecular genetic defects, which cause deficiency in complex I, are subdivided into mtDNA and nuclear gene mutations. Recent findings (10-13) and the present study underline the contribution of mtDNA-encoded complex I subunits in the cause of complex I deficiency associated with encephalomyopathy. It is indeed possible that the mtDNA role might be underrepresented, because a complete mtDNA sequencing approach has not been pursued by many laboratories.

The LS associated with complex I deficiency appears in the first months of life and includes one or more of the following features: developmental delay and regression, hypotonia, spasticity, ataxia, dystonia, and myopathy. Patients often show abrupt metabolic decompensation with infections. Other few cases may be delayed into late childhood. A case of LS associated with muscle complex I deficiency was described in an 8-y-old girl with a mild spastic paraparesis (14) and in a 17-y-old patient with a progressive hypokinetic-rigid syndrome (15).

Mutations in nuclear-encoded complex I subunits have been reported in the nuclear genes NDUFS 2, 4, 7, and 8 and NDUFV1 (16). So far, no clear-cut clinical, radiologic, or biochemical differences in outcome have been helpful in the distinction with mtDNA-related disorders $(17,18)$.

We identified a novel T-to-C mutation at $\mathrm{np} 10158$ in the ND3 subunit gene. This mutation is pathogenic for several reasons. First, it was not found in $>100$ normal individuals. Second, it converts a serine to a proline (i.e. a hydrophilic to a hydrophobic amino acid) at codon 34 in a highly evolutionary conserved amino acid position (Fig. 3). Third, the mutation exists in a heteroplasmic condition (Fig. 3), which is a common feature of pathogenic mtDNA mutation. Fourth, respiratory chain function assays in the proband indicated an isolated complex I deficiency in muscle (Fig. 2). Tissue specificity is also a common feature of pathogenic mtDNA mutation.

It cannot be excluded that the identified mtDNA polymorphisms might have had some effects on cell dysfunction. However, this is unlikely because theses variants do not lead to amino acid changes; they are present as very rare human mtDNA polymorphisms in unaffected individuals (both are independently listed in one mitochondrial genome of 746 available database sequences, www.genpat.uu.se/mtDB/polysites.html) and are also present in a homoplasmic status in the unaffected patient's mother. Therefore, it seems reasonable to conclude that the np 10158 mutation is dominant in this patient.

The absence of T10158C mutation in blood-derived DNA of the patient's mother and her healthy status suggest a sporadic, germ-line origin of this mutation. However, the ND3 mutation could not be investigated in other tissues of this person; therefore, a possibility remains that she carries a variable heteroplasmic level in some of her tissues.

In the majority of LS patients, the onset is in infancy and the prognosis is usually poor because of brainstem dysfunction in an early stage of the disease. In the present patient, the relatively high lactate levels compared with pyruvate and neuroradiologic findings are in accordance with LS. The severity of the proband's clinical features and the relevant biochemical defect suggest a critical functional role of the Ser-34 amino acid within the ND3 subunit.

The function of complex I consists in the transport of electrons from NADH to ubiquinone with shunting of protons across the inner mitochondrial membrane to the intermembrane space: the pathogenic condition of complex I deficiency is correlated with lowered tissue ATP content and increased production of reactive oxygen species (19). The precise function of the ND3 subunit in human complex I is unknown. According to a main model organism to study the complex I and to an analysis by multiple sequence alignment (20), the Ser34Pro mutation may cause instability of the ubiquinone binding site, resulting in defective electron transport. Further studies are needed to provide key information for the roles of ND3 in complex I biogenesis and the genotype-phenotype relationship.

Acknowledgment We thank the "Associazione Amici del Centro Dino Ferrari." The Telethon "Bank of DNA, Nerve and Muscle Tissues" (no. GTF02008) was the source of the skeletal muscle samples used in this study. The Eurobiobank project QLTR-2001-02769 and R.F.2002 "Criobanca automatizzata di materiale biologico" are gratefully acknowledged.

\section{REFERENCES}

1. Leigh D 1951 Subacute necrotizing encephalopathy in an infant. J Neurol Neurosurg Psychiatry 14:216-221

2. DiMauro S, Schon EA 2003 Mitochondrial respiratory-chain diseases. N Engl J Med 348:2656-2668

3. Loeffen JL, Smeitink JA, Trijbels JM, Janssen AJ, Triepels RH, Sengers RC, van den Heuvel LP 2000 Isolated complex I deficiency in children: clinical, biochemical and genetic aspects. Hum Mutat 15:123-134

4. Shoubridge EA 2001 Nuclear genetic defects of oxidative phosphorylation. Hum Mol Genet 10:2277-2284

5. Crimi M, Sciacco M, Galbiati S, Bordoni A, Malferrari G, Del Bo R, Biunno I, Bresolin N, Comi GP 2002 A collection of 33 novel human mtDNA homoplasmic variants. Hum Mutat 20:409

6. Koga Y, Nonaka I, Sunohara N, Yamanaka R, Kumagai K 1988 Variability in the activity in of respiratory chain enzymes in mitochondrial myopathy. Acta Neuropathol 76:135-141

7. Wallace DC, Lott MT 2003 MITOMAP: A Human Mitochondrial Genome Database. Available at: www.mitomap.org

8. Robinson BH 1998 Human complex I deficiency: clinical spectrum and involvement of oxygen free radicals in the pathogenicity of the defect. Biochim Biophys Acta $1364: 271-286$

9. Kirby DM, Crawford M, Cleary MA, Dahl H-HM, X Dennett, Thorburn DR 1999 Respiratory chain complex I deficiency: an underdiagnosed energy generation disorder. Neurology 52:1255-1264

10. Kirby DM, Kahler SG, Freckmann ML, Reddihough D, Thorburn DR 2000 Leigh disease caused by the mitochondrial DNA G14459A mutation in unrelated families. Ann Neurol 48:102-104

11. Taylor RW, Morris AA, Hutchinson M, Turnbull DM 2002 Leigh disease associated with a novel mitochondrial DNA ND5 mutation. Eur J Hum Genet 10:141-144

12. Crimi M, Galbiati S, Moroni I, Bordoni A, Perini MP, Lamantea E, Sciacco M, Zeviani M, Biunno I, Moggio M, Scarlato G, Comi GP 2003 A missense mutation in the mitochondrial ND5 gene associated with a Leigh-MELAS overlap syndrome. Neurology 60:1857-1861

13. Ugalde C, Triepels RH, Coenen MJ, Van Den Heuvel LP, Smeets R, Uusimaa J, Briones P, Campistol J, Majamaa K, Smeitink JA, Nijtmans LG 2003 Impaired complex I assembly in a Leigh syndrome patient with a novel missense mutation in the ND6 gene. Ann Neurol 54:665-669 
14. Van Erven PM, Ruitenbeek W, Gabreels FJ, Renier WO, Fischer JO, Janssen AJ 1986 Disturbed oxidative metabolism in subacute necrotizing encephalomyelopathy (Leigh syndrome). Neuropediatrics 17:28-32

15. Van Erven PM, Gabreels FJ, Ruitenbeek W, Renier WO, Fischer JO 1987 Mitochondrial encephalomyopathy. Association with an NADH dehydrogenase deficiency. Arch Neurol 44:775-778

16. Triepels RH, Van Den Heuvel LP, Trijbels JM, Smeitink JA 2001 Respiratory chain complex I deficiency. Am J Med Genet 106:37-45

17. Loeffen J, Smeitink J, Triepels R, Smeets R, Schuelke R, Sengers R, Trijbels F, Hamel B, Mullaart R, van den Heuvel LP 1998 The first nuclear-encoded com- plex I mutation in a patient with Leigh syndrome. Am J Hum Genet 63:15981608

18. Benit P, Chretien D, Kadhom N, de Lonlay-Debeney P, Cormier-Daire V, Cabral A Pseudenier S, Rustin P, Munnich A, Rotig A 2001 A large-scale deletion and point mutations of the nuclear NDUFV1 and NDUFS1 genes in mitochondrial complex deficiency. Am J Hum Genet 68:1344-1352

19. Bar-Meir M, Elpeleg N, Saada A 2001 Effect of various agents on adenosine triphosphate synthesis in mitochondrial complex I deficiency. J Pediatr 139:868-870

20. Videira A 1998 Complex I from the fungus Neurospora crassa. Biochim Biophys Acta 1364:89-100 